\title{
The burden and correlates of childhood undernutrition in Tanzania according to composite index of anthropometric failure
}

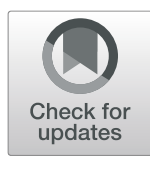

\author{
Ahmed Gharib Khamis ${ }^{1 *} \mathbb{D}$, Akwilina Wendelin Mwanri ${ }^{2}$, Katharina Kreppel ${ }^{3,4}$ and Gideon Kwesigabo ${ }^{1}$
}

\begin{abstract}
Background: Undernutrition is a public health problem worldwide. Tanzania has made significant achievements in the reduction of childhood undernutrition over the past two decades. However, the exact burden of undernutrition was under-estimated when using conventional indices of stunting, wasting and underweight. The objective of this study was to determine the overall prevalence of undernutrition, describe the trends and examine the correlates associated with undernutrition among children under-five years using the composite index of anthropometric failure (CIAF). This study aims to understand the real burden and drivers of undernutrition to improve design, implementation and monitoring of appropriate interventions to ameliorate all form of childhood undernutrition in the country.
\end{abstract}

Methods: About 37,205 mother-child pairs were retrieved and analyzed from the Tanzania Demographic and Health Surveys (TDHS) conducted in various years from 1991, 1996, 1999, 2004-05, 2009-10, to 2015-16. The anthropometric data of children under-five years were used to determine the overall burden and trends of undernutrition using CIAF. The recent TDHS surveys from 2005 to 2015 were used to examine the correlates of CIAF. To determine the correlates, multivariate analysis was conducted to estimate the prevalence ratios (PR) with 95\% confidence intervals (CI) using Poisson regression with robust variance.

Results: The prevalence of CIAF declined significantly from 50\% in 1991 to 38.2\% in 2015 ( $p<0.001)$. The correlates of CIAF vary across surveys. The multivariate analysis of recent 2015 survey revealed that the prevalence of CIAF was significantly higher for older children $(p<0.001)$, children living in rural areas $(p=0.028)$, and those born with noneducated $(p=0.009)$ or single mothers $(p=0.008)$. The prevalence of CIAF was significantly lower for girls ( $p<$ $0.001)$, being born with overweight/obese mothers $(p<0.001)$, living with older head of the household $(p<0.001)$ or living in richest household $(p<0.001)$. Moreover, children who were born with low birth weight $(p<0.001)$, or having fever $(p=0.044)$ were most likely to have anthropometric failure. However, consumption of diversified diet was not found to be associated with anthropometric failure $(p>0.05)$.

(Continued on next page)

\footnotetext{
*Correspondence: ahmadboycd@gmail.com

'Department of Epidemiology and Biostatistics, Muhimbili University of

Health and Allied Sciences, Dar-es-Salaam, Tanzania

Full list of author information is available at the end of the article
}

(c) The Author(s). 2020 Open Access This article is licensed under a Creative Commons Attribution 4.0 International License, which permits use, sharing, adaptation, distribution and reproduction in any medium or format, as long as you give appropriate credit to the original author(s) and the source, provide a link to the Creative Commons licence, and indicate if changes were made. The images or other third party material in this article are included in the article's Creative Commons licence, unless indicated otherwise in a credit line to the material. If material is not included in the article's Creative Commons licence and your intended use is not permitted by statutory regulation or exceeds the permitted use, you will need to obtain permission directly from the copyright holder. To view a copy of this licence, visit http://creativecommons.org/licenses/by/4.0/ The Creative Commons Public Domain Dedication waiver (http://creativecommons.org/publicdomain/zero/1.0/) applies to the data made available in this article, unless otherwise stated in a credit line to the data. 


\begin{abstract}
(Continued from previous page)
Conclusion: About one in every three under-five years children are suffering from either one or multiple forms of anthropometric failure in Tanzania. There is a significant decline trends in overall burden of undernutrition in Tanzania from the past 25 years, as measured by CIAF. Multiple factors including those related to mothers, children and household socio-economic characteristics have the potential to influence childhood undernutrition. Efforts to reduce the burden of undernutrition should mainly focus on reducing poverty and raising people's living standards.
\end{abstract}

Keywords: Children, Stunting, Wasting, Underweight, Anthropometric failure, CIAF, Tanzania

\section{Background}

Undernutrition remains one of the biggest health problems for developing countries [1]. Recent global estimates reported that $45 \%$ of all child deaths are due to various forms of undernutrition [2]. These rates are persistently higher in the Sub-Saharan Africa region [3]. Over the past two decades, Tanzania has seen a significant achievement in reduction of undernutrition owing to rapid decline in stunting and underweight. Despite the significant progress made in the country, the levels are still high $[4,5]$. In 2015, the Tanzania Demographic and Health Survey report showed that the prevalence of chronic undernutrition (stunting) was $34.4 \%$, acute malnutrition (wasting) was $4.5 \%$, and underweight was $13.6 \%$ [5]. Moreover, the recent national nutrition survey conducted in Tanzania found that 10\% of children under-5 years old were severely stunted, and $2.7 \%$ were severely underweight [2]. Given the negative consequences of undernutrition on child health outcomes, there is certainly a need for actions to drawn up policies and programs to identify and implement solutions that will prevent all forms of childhood undernutrition.

The current body of evidence of the prevalence of undernutrition in Tanzania has focused on a single conventional indices such as wasting, stunting and underweight as proposed by the World health organization (WHO) [3]. Studies have shown that conventional indices when used alone, failed to give a true estimates of the real burden of childhood undernutrition. This is because, these indices may overlap, meaning that the same child could show signs of having two or more of these indicators simultaneously [6], and are therefore insufficient for determining the overall burden of undernutrition among under-five children. To compensate, Svedberg et al [7] developed a model known as composite index of anthropometric failure (CIAF) that classifies undernutrition into mutually exclusive groups, enabling the identification of children with more than one form of anthropometric failure [7]. Importantly, this model was evaluated and found to better provide the information on the true prevalence of undernutrition, and thus helps detect children with multiple anthropometric failure [7-9]. Furthermore, the above model has been used in several studies [10,11], and it has been concluded that CIAF invariably identifies a greater percentage of undernourished children compared to conventional indices [12, 13]. Countries such as China, Malawi and others have adopted the CIAF model to redefine their children's nutrition situation [8, 9, 14-18]; but such national wide studies are lacking in Tanzania.

The causes for undernutrition in under-five children are complex and multifaceted. Poor socio-economic conditions, food insecurity, poverty, and adverse conditions such as illness or inadequate feeding practices can drastically alter the growth pattern of children $[19,20]$. According to the UNICEF conceptual framework [21], undernutrition can be caused by insufficient diet intake, infections, poor breastfeeding or inadequate complementary foods. To date, numerous studies have been conducted to examine the determinants of undernutrition in Tanzania $[4,22-24]$ and elsewhere $[15,17,25-$ 27]. However, available studies in the country have used conventional indices, rather than aggregated indicator of CIAF. More studies are therefore needed to reveal the associated factors of anthropometric failure particularly among children in Tanzania.

This study aimed to determine the prevalence of child undernutrition using aggregated index of CIAF from the large datasets of the Tanzania Demographic and Health Surveys (TDHS), and describe the trends from 1991 to 2015. We hypothesized that CIAF will identify significantly higher numbers of children who are undernourished compared to conventional indices. We also sought to examine the correlates of childhood undernutrition according to CIAF. To our knowledge, this is the first attempt to explore the potential correlates of undernutrition using CIAF in Tanzania. This study is crucial to understand the real burden of undernutrition in the country to improve the design, implementation and monitoring of appropriate interventions and ameliorate undernutrition. Moreover, the results will help to track the progress of the country in the attainment of the current World Health Assembly Global Nutrition targets for 2025 [28], and Sustainable Development Goals (SGD 2) by 2030 [29].

\section{Methods}

\section{Sources of data}

The data for this study originates from the Tanzania Demographic and Health Surveys (TDHS) dataset. These 
nationally representative cross-sectional surveys are administered by Inner City Fund (ICF) International since 1991. Six (6) TDHS surveys have been conducted in Tanzania to date (April 2020). These surveys are done regularly after every 5 years to determine levels, patterns, and trends in demographic and health indicators [2]. All enumerators of TDHS received well training before data collection to ensure that all procedure are well followed to achieve comparable results in different countries. The description of the six surveys conducted in Tanzania is shown in Table 1.

\section{TDHS sampling}

The TDHS are national socio-demographic surveys that collect information based on a stratified two-stage cluster sampling design. First, sample clusters are selected followed by households selection from each of the selected clusters using equal probability systematic sampling. All men aged 15-59 years and women aged 1549 years old in the selected households are eligible to be interviewed if they were either usual residents of that household or visitors on the night before the survey. Among the variables collected by the TDHS is information on the mothers and their children aged 0 to 59 months, such as anthropometry, feeding practices, vaccination status, birth interval, childhood morbidity and mortality, and use of maternal and child health services [2]. We managed to extract the information of motherchild pairs in TDHS across the years as follows; 1991 $(n=6177), 1996 \quad(n=5226), 1999 \quad(n=3008), 2004-05$ ( $n=7107), 2009-10(n=6774)$, and 2015-16 $(n=8913)$. However, in identifying correlates of CIAF only recent TDHS surveys of 2004-05, 2010 and 2015-16 were used because they have many variables that were collected and presented in a similar manner.

\section{Anthropometric measurements}

In all TDHS surveys, anthropometric measurements were taken according to international and national recommended procedures by the WHO. Body weight and height/length of all eligible children were measured according to standard procedures developed by $\mathrm{WHO}$ and UNICEF, and the nutritional status of the children (under 5 years old) was calculated. We extracted anthropometric information of all children in the children datasets. According to the WHO, all children with Z-scores of Height for age (HAZ), weight-for height (WHZ) or weight-for age (WAZ) below - 2 standard deviations (SD), with respect to the standards of the WHO were considered being stunted, underweight or wasting; respectively.

\section{Determination of the composite index of anthropometric failure (CIAF)}

The main outcome (dependent) variable of interest was undernutrition as measured by using CIAF. This index identifies seven groups used to classify undernutrition as follows: A (no anthropometric failure), B (wasting only), $\mathrm{C}$ (wasting and underweight), D (wasting, stunting and underweight), $\mathrm{E}$ (stunting and underweight) and $\mathrm{F}$ (stunting only), and Y (Underweight only) [7, 9]. The CIAF is calculated by subtracting the group A children from the total number. Therefore, a child is regarded as undernourished as measured by CIAF if he/she suffered any anthropometric failure above (B to $\mathrm{Y}$ ). The CIAF is a binary variable, which is 1 if a child is either stunted, underweight, wasted or any combination of the three and 0 if not, as described in Table 2.

\section{Other independent variables}

We adopted other covariates as suggested by the UNICEF conceptual framework of malnutrition and after reviewing available literature [4]. Covariates include variables for the age and gender of the child. Child age was classified into four categories: < 6 months, between 6 and 23 months, $24-35$ months, and $>35$ months. Further covariates included place of residence of the household (including rural versus urban), marital status of the mother as category: married, single, divorced/death. We selected categorized initiation of breastfeeding either within $1 \mathrm{~h}$ after birth, after $1 \mathrm{~h}$, or after 1 day. Other child's characteristics as reported by the mother included mother's perceived birth size (size of child as reported by the mother), place of delivery (home, health facility or other places), and symptoms of fever and/or diarrhea in the child in the past 2 weeks before the interview (Yes/No). Mothers characteristics like age at first birth (years), highest level of education (primary,

Table 1 Demographic and Health Surveys conducted in Tanzania to date and the number of children included for the study

\begin{tabular}{llr}
\hline Year & Name of the survey & Number of children included in the study (N) \\
\hline 1991 & Tanzania Demographic and Health Survey (TDHS, 1991-92) & 5177 \\
1996 & Tanzania Demographic and Health Survey (TDHS, 1996) & 3008 \\
$2004-05$ & Tanzania Reproductive and Child Health Survey (TRCHS) & 7107 \\
2010 & Tanzania Demographic and Health Survey (TDHS 2004-05) & 6774 \\
2015 & Tanzania Demographic and Health Survey (TDHS 2010) & 8913 \\
\hline
\end{tabular}


Table 2 Prevalence of composite index of anthropometric failure in Tanzania (1991-2015)

\begin{tabular}{|c|c|c|c|c|c|c|c|c|}
\hline \multicolumn{2}{|c|}{ CIAF categories } & \multirow{2}{*}{$\frac{1991}{50.0}$} & \multirow{2}{*}{$\begin{array}{l}1996 \\
49.0\end{array}$} & \multirow{2}{*}{$\begin{array}{l}1999 \\
50.2\end{array}$} & \multirow{2}{*}{$\begin{array}{l}2004-05 \\
57.8\end{array}$} & \multirow{2}{*}{$\begin{array}{l}2010-11 \\
54.1\end{array}$} & \multirow{2}{*}{$\begin{array}{l}2015-16 \\
61.7\end{array}$} & \multirow{2}{*}{$\frac{P \text {-value }}{<0.001}$} \\
\hline A & No failure (\%) & & & & & & & \\
\hline B & Wasting only (\%) & 1.1 & 1.1 & 0.8 & 0.4 & 1.3 & 1.6 & $<0.001$ \\
\hline C & Wasting and underweight (\%) & 2.8 & 3.0 & 1.8 & 1.3 & 1.7 & 1.3 & $<0.001$ \\
\hline D & Wasting. Stunting and underweight (\%) & 2.2 & 3.2 & 2.7 & 1.3 & 1.8 & 1.5 & $<0.001$ \\
\hline E & Stunting and underweight (\%) & 21.0 & 21.0 & 21.5 & 16.5 & 11.4 & 9.7 & $<0.001$ \\
\hline $\mathbf{F}$ & Stunting only (\%) & 20.1 & 19.3 & 19.5 & 19.9 & 28.8 & 23.2 & $<0.001$ \\
\hline \multirow[t]{3}{*}{$\mathrm{Y}$} & Underweight only (\%) & 3.0 & 3.5 & 3.4 & 2.8 & 0.9 & 0.9 & $<0.001$ \\
\hline & CIAF, $(\%)^{\mathrm{a}}$ & 50.0 & 51.0 & 49.8 & 42.2 & 45.9 & 38.2 & $<0.001$ \\
\hline & Total (\%) & 100 & 100 & 100 & 100 & 100 & 100 & \\
\hline
\end{tabular}

* $P$-value for trends from 1991 to 2015

$\mathrm{a}=\mathrm{CIAF}=\mathrm{B}+\mathrm{C}+\mathrm{D}+\mathrm{E}+\mathrm{F}+\mathrm{Y}$

secondary or higher), employment status, and number of children born in the past 5 years were also included, as reported and categorized in the previous studies [4, 23]. Mother's body mass index (BMI) was determined using the WHO cut-off point of: $<18.5 \mathrm{~kg} / \mathrm{m}^{2}$ as underweight, $18.5-25 \mathrm{~kg} / \mathrm{m}^{2}$ as normal, $25-30 \mathrm{~kg} / \mathrm{m}^{2}$ as overweight, and above $30 \mathrm{~kg} / \mathrm{m}^{2}$ as obese. Other household information included are gender (Male/Female) and age of the household head categorized into: 15-29 years, 30-49 years and $\geq 50$ years. Wealth index derived from principal component analysis from TDHS were used in this analysis, and it was divided into quintiles of poorest, poorer, middle, richer and richest $[2,4,5]$.

\section{Dietary diversity determination}

Children aged 6 to 23 months with dietary intake information such as food groups consumed in the previous day were selected for sub-group analysis. The dietary intake information was extracted in the mother dataset. In TDHS, all mothers were asked to report different types of foods given to their children in the previous $24 \mathrm{~h}$ before the interview. A minimum dietary diversity (MDD) was used to determine the diversity of complementary foods as suggested by the WHO's infant and young child feeding guideline [30]. The MDD was attained if a child had consumed four or more food groups out of the seven. The details of how the MDD was constructed can be found in previous study [31].

\section{Statistical analysis}

Data analysis was conducted using the Statistical Package for Social Sciences (Version 23.0; IBM Corp., Armonk, NY, USA). Data extraction and cleaning was conducted using Stata version 13 (Stata SE/13). Both descriptive and regression analysis were used in this study. Firstly, descriptive statistics was used to obtain prevalence estimates and trends of CIAF among children of 0 to 59 months using data from all six TDHS studies (1991 to 2015$)$ using a binary variable $(1=$ Yes; $0=$ No).
Differences in prevalence rates between survey-years were examined using chi-squared test. In the second part, we used Poisson regression with robust variance to identify the correlates of CIAF in order to have a better estimate of the associations. This is because the outcomes is common with high prevalence of more than $10 \%$ [32]. Both crude and adjusted prevalence ratios (PR) with 95\% confidence intervals (CI) were estimated. At first, crude PR was estimated to identify variables associated with CIAF. Next, Multivariable analysis was conducted; adjusted prevalence ratios (APR) were estimated by entering all variables in the model. Variables with $p<0.05$ in the multivariate model were considered to be a significant correlates of CIAF.

\section{Results}

Background characteristics of the included mother and children in TDHS 2005-2015

About 37,205 children-mothers pairs were extracted from TDHS from 1991 to 2015. Table 3 presents the background characteristics of the included mother-child pairs from the recent surveys from 2005 to 2015. The majority of the included children $\sim 50 \%$ were girls. About one third $(\sim 30 \%)$ of the children were between the ages of above 35 months followed by 6 to 23 months old. The majority of the children (about 45 to $50 \%$ ) had normal weight at birth, just less than $4 \%$ were below the normal birth weight, and some have not reported their birth weight ( $30-50 \%)$. More than $70 \%$ of all children were recorded to live in rural areas for all surveys. Less than $20 \%$ of the sampled children had diarrhea and/or symptoms of fever within 2 weeks preceding the survey.

Among mothers, more than half were between the ages of 25 to 39 years. The proportion of mothers without any formal education had decreased from $27 \%$ in 2004-05 to $21 \%$ in 2015-2016. Nevertheless, in the same period, the proportion of mothers who attained higher education, past primary school remained the same. Some of them initiated breastfeeding within an 
Table 3 Descriptive characteristics of the included mothers and children in the Tanzania Demographic and Health Survey (20052015)

\begin{tabular}{|c|c|c|c|}
\hline \multirow[t]{3}{*}{ Variables } & 2014-15 & 2010 & 2004-05 \\
\hline & $(\boldsymbol{N}=8913)$ & $(\boldsymbol{N}=6774)$ & $(\boldsymbol{N}=7107)$ \\
\hline & $\boldsymbol{n}(\%)$ & $\boldsymbol{n}(\%)$ & $\boldsymbol{n}(\%)$ \\
\hline \multicolumn{4}{|l|}{ Household's Characteristics } \\
\hline \multicolumn{4}{|l|}{ Residence } \\
\hline Urban & $2013(22.6)$ & $1231(18.2)$ & $1210(17)$ \\
\hline Rural & $6900(77.4)$ & $5543(81.8)$ & $5897(82.9)$ \\
\hline \multicolumn{4}{|c|}{ Gender of household head } \\
\hline Male & $7501(84.2)$ & $5681(83.9)$ & 5974(84) \\
\hline Female & $1412(15.8)$ & 1093(16.1) & 1133(15.9) \\
\hline \multicolumn{4}{|c|}{ Age of the household head (years) } \\
\hline 15 to 29 & $1462(16.4)$ & 1095(16.2) & 1426(20.1) \\
\hline 30 to 49 & $5269(59.1)$ & $4142(61.1)$ & $4099(57.7)$ \\
\hline Above 50 & $2185(24.5)$ & $1537(22.7)$ & 1582(22.2) \\
\hline \multicolumn{4}{|l|}{ Household wealth } \\
\hline Poorest & $2064(23.2)$ & $1387(20.5)$ & 1569(22.1) \\
\hline Poorer & 1859(20.9) & 1561(22.9) & 1421(19.9) \\
\hline Middle & $1740(19.5)$ & $1449(21.4)$ & 1439(20.2) \\
\hline Richer & 1836(20.6) & $1389(20.5)$ & 1573(22.2) \\
\hline Richest & 1414(15.9) & $988(14.7)$ & $1105(15.5)$ \\
\hline \multicolumn{4}{|l|}{ Mother's Characteristics } \\
\hline \multicolumn{4}{|l|}{ Mothers BMI } \\
\hline Underweight & $643(7.2)$ & $663(9.8)$ & $622(8.8)$ \\
\hline Normal & $5990(67.2)$ & $4768(70.4)$ & $5390(75.8)$ \\
\hline Overweight & $1548(17.4)$ & $1000(14.8)$ & $825(11.6)$ \\
\hline Obesity & $732(8.22)$ & $343(5.1)$ & $270(3.8)$ \\
\hline \multicolumn{4}{|l|}{ Age of mother (years) } \\
\hline $15-24$ & $2589(29.1)$ & 1824(26.9) & $2051(28.8)$ \\
\hline $25-39$ & $5333(59.8)$ & $4211(62.1)$ & $4424(62.3)$ \\
\hline $40-49$ & $991(11.1)$ & 739(10.9) & $632(8.9)$ \\
\hline \multicolumn{4}{|l|}{ Marital status of mother } \\
\hline Single & $418(4.7)$ & $279(4.1)$ & $267(3.7)$ \\
\hline Married/with partner & $7607(85.3)$ & $5910(87.2)$ & $6286(88.4)$ \\
\hline Divorced/separated & 888(9.9) & $585(8.6)$ & $554(7.8)$ \\
\hline \multicolumn{4}{|c|}{ Mothers age at first birth (years) } \\
\hline$<15$ & $220(2.5)$ & $202(2.9)$ & $246(3.5)$ \\
\hline $15-29$ & 8590(96.4) & $6516(96.2)$ & $6811(95.8)$ \\
\hline $30-50$ & 103(1.15) & $56(0.8)$ & $50(0.7)$ \\
\hline \multicolumn{4}{|l|}{ Number of birth } \\
\hline One & $3827(42.9)$ & 2650(39) & 2723(38.3) \\
\hline Two & 4059(45.6) & $3294(48.5)$ & $3454(48.5)$ \\
\hline Three and above & $1027(11.5)$ & $848(12.5)$ & $930(13.1)$ \\
\hline \multicolumn{4}{|l|}{ Education of mother } \\
\hline No education & 1948(21.8) & $1734(25.5)$ & 1949(27.4) \\
\hline
\end{tabular}


Table 3 Descriptive characteristics of the included mothers and children in the Tanzania Demographic and Health Survey (20052015) (Continued)

\begin{tabular}{|c|c|c|c|}
\hline \multirow[t]{3}{*}{ Variables } & $2014-15$ & 2010 & 2004-05 \\
\hline & $(\boldsymbol{N}=8913)$ & $(\boldsymbol{N}=6774)$ & $(\boldsymbol{N}=7107)$ \\
\hline & n (\%) & n (\%) & $\boldsymbol{n}(\%)$ \\
\hline Primary & $5359(60.1)$ & $4271(63)$ & $4564(64.2)$ \\
\hline Secondary & $1528(17.2)$ & $751(11.2)$ & $510(7.2)$ \\
\hline Higher & $80(0.9)$ & $18(0.3)$ & $84(1.2)$ \\
\hline \multicolumn{4}{|l|}{ Children's Characteristics } \\
\hline \multicolumn{4}{|c|}{ Age of child (months) } \\
\hline$<6$ & $975(10.9)$ & $738(10.9)$ & $758(10.6)$ \\
\hline 6 to 23 & $3070(34.4)$ & $2207(32.6)$ & 2399(33.7) \\
\hline $24-35$ & $1728(19.4)$ & $1268(18.8)$ & 1460(20.6) \\
\hline$>35$ & $3140(35.2)$ & $2561(37.8)$ & $2490(35.1)$ \\
\hline \multicolumn{4}{|l|}{ Gender of child } \\
\hline Male & $4471(50.2)$ & $3365(49.7)$ & $3556(50)$ \\
\hline Female & $4442(49.8)$ & $3409(50.3)$ & $3551(49.9)$ \\
\hline \multicolumn{4}{|l|}{ Birth weight } \\
\hline Above $2500 \mathrm{~g}$ & $5148(57.8)$ & $3260(48.2)$ & $3202(45)$ \\
\hline Below $2500 \mathrm{~g}$ & $347(3.9)$ & 215(3.2) & $245(3.4)$ \\
\hline Not reported & $3418(38.5)$ & $3299(48.7)$ & $3660(51.5)$ \\
\hline \multicolumn{4}{|c|}{ Employment of mother } \\
\hline Not working & $2257(25.3)$ & 1409(20.8) & 964(13.6) \\
\hline Last year & $420(4.7)$ & $147(2.2)$ & $302(4.3)$ \\
\hline Working currently & $6236(69.9)$ & $5218(77)$ & $5841(82.1)$ \\
\hline \multicolumn{4}{|l|}{ Place of delivery } \\
\hline Health facility & $5462(61.3)$ & $3258(48.1)$ & $3230(45.4)$ \\
\hline At home & $3314(37.2)$ & $3430(50.6)$ & $3871(54.5)$ \\
\hline Other places & 139(1.6) & $86(1.2)$ & $4(0.1)$ \\
\hline \multicolumn{4}{|l|}{ Diarrhea } \\
\hline No & 7837(97.9) & $5813(85.8)$ & $6120(86.2)$ \\
\hline Yes & $1081(12.1)$ & $961(14.2)$ & 987(13.8) \\
\hline \multicolumn{4}{|l|}{ Symptoms of fever } \\
\hline No & $7317(82.1)$ & $5244(77.5)$ & $5105(71.9)$ \\
\hline Yes & 1596(17.9) & $1524(22.5)$ & 1999(28.1) \\
\hline \multicolumn{4}{|c|}{ Initiationof breastfeeding } \\
\hline Within an hour & $3344(37.5)$ & 2296(33.8) & $3946(55.5)$ \\
\hline After an hour & $2699(30.3)$ & 2090(30.8) & 2559(35.9) \\
\hline After one day & $2870(32.2)$ & 2394(35.3) & $602(8.5)$ \\
\hline
\end{tabular}

hour after birth, however, the proportion declined from 55.5 to $37.5 \%$ in 10 years. The proportion of mothers who gave birth below the age of 15 years had slightly declined from $3.5 \%$ in 2005 to $2.5 \%$ in 2015 . Moreover, the proportion of mothers with three or more children declined from $13.1 \%$ in 2005 to $11.5 \%$ in 2015 . According to their nutritional status, the proportion of underweight mothers $\left(<18.5 \mathrm{~kg} / \mathrm{m}^{2}\right)$ declined slightly from $8.8 \%$ in 2005 to $7.2 \%$ in 2015 , while the proportion of obesity more than doubled from 3.8 to $8.2 \%$. Across the surveys, the proportion of richest households, classified using wealth index ranged below 15\%, while the poorest 
household were above $20 \%$. Overall, the majority of households are headed by male and those aged between 30 to 49 years old (Table 3 ).

\section{Prevalence and trends of anthropometric failure (1991- 2015)}

Figure 1 shows the trends in prevalence of CIAF and conventional indices of stunting $(\mathrm{HAZ}<-2 \mathrm{SD})$, wasting (WHZ <-2SD) and underweight (WAZ <-2SD) from 1991 to 2015 in Tanzania. This analysis observed a significant declining trends of anthropometric failure from the past 25 years in Tanzania $(p<0.001)$. In 1991, about half (50\%) of surveyed children had anthropometric failures compared to one in three $(38.2 \%)$ in 2015 . Similarly, for the wasting, stunting and underweight $(p<0.001)$. However, during 2005-2010 the prevalence of stunting and wasting and CIAF worsen slightly. In 1991, about half (50\%) of the surveyed children did not have any form of anthropometric failure (Group A); whereas, more than half $(62 \%)$ of children had no anthropometric failures in 2015 (Table 2). The prevalence of children who have multiple anthropometric failures (Group D) significantly declined from 2.2 to $1.5 \%$ over two and half decades $(p<$ $0.001)$, however, it worsened slightly in 1996 (3.2\%) and 1999 (2.7\%). On the other hand, the prevalence of children with stunting only (Group F) disproportionally changes from 1991 (20.1\%) to 2015 (23.2\%). The prevalence of children with wasting only (Group B) significantly inclined from 1.1 to $1.6 \%$; meanwhile, the proportion of children with underweight only (Group Y) significantly declined from 3 to $0.9 \% 1991$ to 2015 .
Factors associated with anthropometric failure (20052015)

Table 4 presents the results from univariate and multivariate Poisson regression analysis using 2005, 2010 and 2015 TDHS data. In the multivariate model, place of residence, mothers BMI, age of the household head, mother marriage status, education of mother, wealth status, birth weight, age and gender of the children, diarrhea, symptoms of fever and place of delivery were associated with anthropometric failure in various years.

The prevalence of anthropometric failure for rural children increased significantly $(\mathrm{APR}=1.11,95 \% \mathrm{CI}$, $1.01-1.21, p=0.028)$ in 2015. The prevalence of having anthropometric failure reduced significantly based on increasing BMI of the mother. In 2015, the prevalence were lower when mothers were normal $(\mathrm{APR}=0.86,95 \%$ CI, 0.79-0.95, $p=0.001)$, overweight $(\mathrm{APR}=0.79,95 \%$ CI, $0.71-0.88, p<0.001)$ or obese $(\mathrm{APR}=0.65,95 \% \mathrm{CI}$, $0.56-0.76, p<0.001)$ compared to underweight mothers. This result shows that the prevalence of having anthropometric failure reduced among married mothers compared to single mothers in 2015 (APR $=0.84,95 \%$ CI, 0.74-0.96, $p=0.008$ ). The prevalence also reduced if the age of the household head was between 30 and 49 years $(\mathrm{APR}=0.92,95 \% \mathrm{CI}, 0.85-0.98, p=0.015)$, and above 50 years $(\mathrm{APR}=0.85,95 \% \mathrm{CI}, 0.78-0.92, p<0.001)$ compared to younger age of 15-29 years in 2015. Moreover, household wealth status was strongly associated with anthropometric failure in all years. In 2015, results show that the prevalence of anthropometric failure reduced significantly from poorest families to richer $(\mathrm{APR}=0.86,95 \% \mathrm{CI}, 0.79-0.94, p=0.002)$ and richest

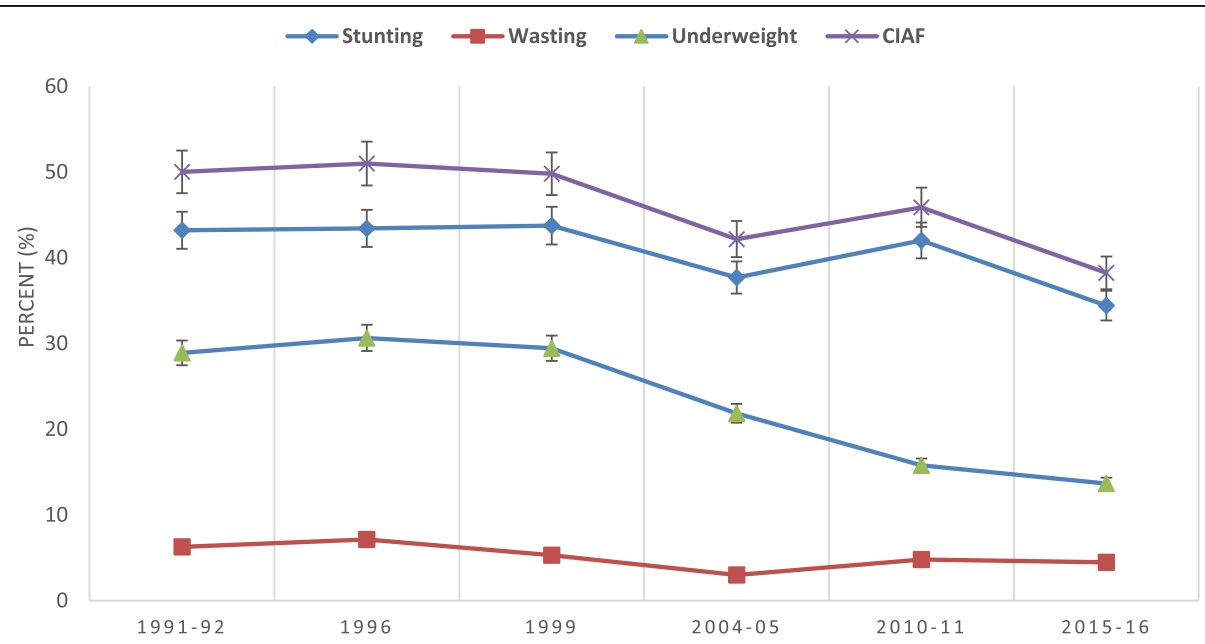

Fig. 1 Trends in prevalence of under-nutrition in Tanzania as classified by CIAF and conventional indices of stunting (HAZ<-2SD), wasting (WHZ<-2SD) and underweight (WAZ<-2SD) from 1991 to 2015. $P$-values for trend in stunting $(X 2=267.42, p<0.001)$; wasting $(X 2=117.73, p<0.001)$; underweight $(X 2=$ 988.89, $p<0.001)$, and $\operatorname{CIAF}(X 2=413.67, p<0.001)$. 
Table 4 Crude and adjusted factors associated with anthropometric failure among children under 5 years of age in Tanzanian Demographic and Health Surveys (2005-2015)

\begin{tabular}{|c|c|c|c|c|c|c|}
\hline \multirow[b]{2}{*}{ Variables } & \multicolumn{2}{|l|}{ TDHS 2014-15 } & \multicolumn{2}{|l|}{ TDHS 2010} & \multicolumn{2}{|l|}{ TDHS 2004-05 } \\
\hline & $\begin{array}{l}\text { PR } \\
(95 \% \mathrm{Cl})\end{array}$ & $\begin{array}{l}\text { Adjusted PR } \\
(95 \% \mathrm{Cl})\end{array}$ & $\begin{array}{l}\text { PR } \\
(95 \% \mathrm{Cl})\end{array}$ & $\begin{array}{l}\text { Adjusted PR } \\
(95 \% \mathrm{Cl})\end{array}$ & $\begin{array}{l}\text { PR } \\
(95 \% \mathrm{Cl})\end{array}$ & $\begin{array}{l}\text { Adjusted PR } \\
(95 \% \mathrm{Cl})\end{array}$ \\
\hline \multicolumn{7}{|l|}{ Residence } \\
\hline Urban & 1.0 & 1.0 & 1.0 & 1.0 & 1.0 & NA \\
\hline Rural & $1.39(1.29-1.51)^{* * *}$ & $1.11(1.01-1.21)^{*}$ & $1.36(1.25-1.47)^{* * *}$ & $1.12(1.01-1.23)^{*}$ & $1.36(1.25-1.49)^{*}$ & \\
\hline \multicolumn{7}{|l|}{ Mothers BMI } \\
\hline Underweight & 1.0 & 1.0 & 1.0 & 1.0 & 1.0 & \\
\hline Normal & $0.86(0.78-0.94)^{* *}$ & $0.86(0.79-0.95)^{* *}$ & $0.82(0.76-0.88)^{* * *}$ & $0.85(0.79-0.92)^{* * *}$ & $0.87(0.81-0.95)^{* * *}$ & $0.88(0.82-0.95)^{* *}$ \\
\hline Overweight & $0.72(0.64-0.79)^{* * *}$ & $0.79(0.71-0.88)^{* * *}$ & $0.69(0.62-0.76)^{* * *}$ & $0.78(0.70-0.86)^{* * *}$ & $0.64(0.56-0.73)^{* * *}$ & $0.74(0.65-0.84)^{* * *}$ \\
\hline Obesity & $0.52(0.45-0.61)^{* *}$ & $0.65(0.56-0.76)^{* * *}$ & $0.51(0.42-0.61)^{* * *}$ & $0.61(0.51-0.74)^{* * *}$ & $0.48(0.38-0.60)^{* * *}$ & $0.66(0.53-0.82)^{* * *}$ \\
\hline \multicolumn{7}{|c|}{ Mothers age at first birth } \\
\hline$<15$ & 1.0 & NA & 1.0 & NA & 1.0 & NA \\
\hline $15-29$ & $0.86(0.74-1.00)$ & & $0.99(0.85-1.16)$ & & $0.94(0.81-1.08)$ & \\
\hline $30-50$ & $0.80(0.59-1.08)$ & & $0.90(0.64-1.27)$ & & $0.90(0.63-1.30)$ & \\
\hline \multicolumn{7}{|c|}{ Number of birth in the five years } \\
\hline One & 1.0 & NA & 1.0 & NA & 1.0 & NA \\
\hline Two & $1.03(0.97-1.09)$ & & $1.1(1.04-1.16)^{* *}$ & & $1.01(0.96-1.08)$ & \\
\hline Three and above & $1.03(0.95-1.13)$ & & $1.05(0.96-1.14)$ & & $0.90(0.82-0.99)$ & \\
\hline \multicolumn{5}{|c|}{ Gender of the head of the household } & & NA \\
\hline Male & 1.0 & NA & 1.0 & NA & 1.0 & \\
\hline Female & $1.06(0.99-1.14)$ & & $1.01(0.94-1.09)$ & & $1.09(1.02-1.17)^{*}$ & \\
\hline \multicolumn{7}{|c|}{ Age of the head of the household } \\
\hline 15 to 29 & 1.0 & 1.0 & 1.0 & NA & 1.0 & 1.0 \\
\hline 30 to 49 & $0.91(0.85-0.98)^{*}$ & $0.92(0.85-0.98)^{*}$ & $0.98(0.91-1.05)$ & & $0.93(0.86-0.99)^{*}$ & $0.92(0.86-0.98)^{*}$ \\
\hline Above 50 & $0.88(0.81-0.95)^{* *}$ & $0.85(0.78-0.92)^{* * *}$ & $0.92(0.85-1.00)$ & & $0.94(0.86-1.02)$ & $0.91(0.84-0.98)^{*}$ \\
\hline \multicolumn{7}{|l|}{ Mother education } \\
\hline No education & 1.0 & 1.0 & 1.0 & NA & 1.0 & \\
\hline Primary & $0.92(0.86-0.97)^{* *}$ & $0.96(0.91-1.03)$ & $0.94(0.88-0.99)^{*}$ & & $0.89(0.84-0.95)^{* * *}$ & $0.99(0.93-1.05)$ \\
\hline Secondary & $0.69(0.63-0.75)^{* * *}$ & $0.86(0.77-0.96)^{* *}$ & $0.68(0.61-0.76)^{* * *}$ & & $0.59(0.52-0.69)^{* * *}$ & $0.85(0.73-0.98)^{*}$ \\
\hline Higher & $0.26(0.14-0.49)^{* * *}$ & $0.43(0.23-0.82)^{*}$ & $0.45(0.19-1.07)$ & & $0.20(0.11-0.39)^{* * *}$ & $0.40(0.21-0.76)^{* *}$ \\
\hline \multicolumn{7}{|l|}{ Mothers marriage } \\
\hline Single & 1.0 & 1.0 & 1.0 & NA & 1.0 & 1.0 \\
\hline Married & $0.95(0.84-1.07)$ & $0.84(0.74-0.96)^{* *}$ & $1.06(0.92-1.22)$ & & $0.91(0.79-1.05)$ & $0.85(0.74-0.96)^{*}$ \\
\hline Separated & $1.04(0.90-1.20)$ & $0.90(0.78-1.04)$ & $1.09(0.93-1.29)$ & & $1.06(0.90-1.24)$ & $0.92(0.79-1.07)$ \\
\hline \multicolumn{7}{|l|}{ Wealth status } \\
\hline Poorest & 1.0 & 1.0 & 1.0 & 1.0 & 1.0 & 1.0 \\
\hline Poorer & $1.01(0.93-1.08)$ & $0.99(0.92-1.06)$ & $0.92(0.85-0.98)^{*}$ & $0.94(0.87-1.00)$ & $0.96(0.89-1.03)$ & $0.96(0.89-1.03)$ \\
\hline Middle & $1.01(0.94-1.09)$ & $1.02(0.95-1.11)$ & $0.88(0.83-0.95)^{* *}$ & $0.93(0.86-0.99)^{*}$ & $0.89(0.83-0.96)^{* *}$ & $0.92(0.86-0.99)^{*}$ \\
\hline Richer & $0.79(0.73-0.86)^{* * *}$ & $0.86(0.79-0.94)^{* *}$ & $0.78(0.72-0.84)^{* * *}$ & $0.87(0.78-0.95)^{* *}$ & $0.79(0.73-0.86)^{* * *}$ & $0.85(0.78-0.92)^{* * *}$ \\
\hline Richest & $0.68(0.53-0.65)^{* * *}$ & $0.74(0.64-0.84)^{* * *}$ & $0.62(0.56-0.68)^{* * *}$ & $0.79(0.69-0.91)^{* *}$ & $0.44(0.39-0.49)^{* * *}$ & $0.53(0.46-0.61)^{* * *}$ \\
\hline \multicolumn{7}{|c|}{ Age of child (months) } \\
\hline$<6$ & 1.0 & 1.0 & 1.0 & 1.0 & 1.0 & 1.0 \\
\hline 6 to 23 & $1.51(1.34-1.71)^{* * *}$ & $1.48(1.31-1.67)^{* * *}$ & $1.65(1.46-1.88)^{* * *}$ & $1.64(1.44-1.86)^{* * *}$ & $4.99(3.96-6.28)^{* * *}$ & $4.61(3.66-5.80)^{* * *}$ \\
\hline
\end{tabular}


Table 4 Crude and adjusted factors associated with anthropometric failure among children under 5 years of age in Tanzanian Demographic and Health Surveys (2005-2015) (Continued)

\begin{tabular}{|c|c|c|c|c|c|c|}
\hline \multirow[b]{2}{*}{ Variables } & \multicolumn{2}{|l|}{ TDHS 2014-15 } & \multicolumn{2}{|l|}{ TDHS 2010} & \multicolumn{2}{|l|}{ TDHS 2004-05 } \\
\hline & $\begin{array}{l}\mathrm{PR} \\
(95 \% \mathrm{Cl})\end{array}$ & $\begin{array}{l}\text { Adjusted PR } \\
(95 \% \mathrm{Cl})\end{array}$ & $\begin{array}{l}\mathrm{PR} \\
(95 \% \mathrm{Cl})\end{array}$ & $\begin{array}{l}\text { Adjusted PR } \\
(95 \% \mathrm{Cl})\end{array}$ & $\begin{array}{l}\mathrm{PR} \\
(95 \% \mathrm{Cl})\end{array}$ & $\begin{array}{l}\text { Adjusted PR } \\
(95 \% \mathrm{Cl})\end{array}$ \\
\hline $24-35$ & $1.89(1.67-2.13)^{* * *}$ & $1.86(1.64-2.11)^{* * *}$ & $1.99(1.75-2.26)^{* * *}$ & $1.98(1.74-2.25)^{* * *}$ & $5.14(4.07-6.49)^{* * *}$ & $4.97(3.92-6.27)^{*}$ \\
\hline$>35$ & $1.59(1.41-1.79)^{* * *}$ & $1.59(1.40-1.81)^{* * *}$ & $1.61(1.42-1.82)^{* * *}$ & $1.57(1.37-1.80)^{* * *}$ & $5.13(4.07-6.46)^{* * *}$ & $4.99(3.96-6.27)^{*}$ \\
\hline
\end{tabular}

\section{Gender of children}

$\begin{array}{lllllll}\text { Male } & 1.0 & 1.0 & 1.0 & 1.0 & 1.0 & 1.0 \\ \text { Female } & 0.88(0.83-0.93)^{* * *} & 0.87(0.83-0.92)^{* * *} & 0.85(0.81-0.89)^{* * *} & 0.84(0.80-0.88)^{* * *} & 0.94(0.89-0.99)^{*} & 0.95(0.89-0.99)^{*}\end{array}$

\section{Birth weight}

Above $2500 \mathrm{~g}$

Below $2500 \mathrm{~g}$

$1.64(1.48-1.81)^{* * *}$

1.0

$1.65(1.48-1.82)^{* * *}$

1.0

$1.47(1.31-1.66)^{* * *}$

1.0

$1.51(1.34-1.69)^{* * *}$

1.0

$1.65(1.47-1.85)^{* * *}$

1.0

$1.59(1.42-1.79)^{* * *}$

NA

0.99(0.86-1.15)

Last year

$1.10(1.02-1.18)^{*}$

Working currently

Place of delivery

Health facility

At home

Other places

1.0

$1.19(1.13-1.26)^{* * *}$

1.00(0.79-1.25)

Presence of diarrhea

No

Yes

1.0

1.05(0.97-1.14)

Symptoms of fever

No

Yes

1.0

$1.10(1.03-1.18)^{* *}$

1.0

$1.07(1.00-1.14)^{*}$

\section{Starting of breastfeeding}

Within an hour $\quad 1.0$

After an hour 1.0(0.94-1.07)

After one day $\quad 1.10(1.03-1.17)^{* *}$
NA

1.0

1.05(0.98-1.13)

$1.15(1.08-1.23)^{* * * *}$
1.0

1.03(0.97-1.09)

NA

$1.08(1.00-1.17)^{*}$

1.0

$1.18(1.13-1.25)^{* * *}$

$1.24(1.00-1.53)^{*}$

1.0

1.06(0.98-1.14)

NA

NA

$1.27(1.20-1.35)^{* * *}$

$0.68(0.12-3.76)$

1.0

$1.16(1.06-1.27)^{* * *}$

$0.69(0.16-3.03)$

1.0

$1.21(1.13-1.29)^{* * *}$

$1.12(1.04-1.20)^{* *}$

NA

1.0

$1.17(1.11-1.24)^{* * *}$

1.0

$1.08(1.02-1.15)^{* *}$

NA

1.0

NA

$1.11(1.04-1.17)^{* *}$

$1.12(1.02-1.24)^{*}$
0.88(0..70-1.09)

${ }^{* *} P<.01,{ }^{*} P<.05,{ }^{* * *} P<0.001 ; 1.0=$ Reference category, $\mathrm{Cl}=$ Confidence interval; $P R$ Prevalence ratio, $N A=$ Not significant in the multivariate model

families $(\mathrm{APR}=0.74,95 \% \mathrm{CI}, 0.64-0.84, p<0.001)$. Mothers having a higher level of education showed less prevalence of anthropometric failure $(\mathrm{APR}=0.43,95 \%$ CI, 0.23-0.82, $p=0.009)$ compared to mothers with no formal education in 2015.

Both age and gender of the children are associated with anthropometric failure across all years. The prevalence of anthropometric failure increased for children aged between 6 and 23 months $(\mathrm{APR}=1.48,95 \% \mathrm{CI}$, $1.31-1.67, p<0.001), 24-35$ months $(\mathrm{APR}=1.86,95 \%$ CI, 1.64-2.11, $p<0.001)$ and more than 35 months $(\mathrm{APR}=1.59,95 \% \mathrm{CI}, 1.40-1.81, p<0.001)$ compared to children aged less than 6 months in 2015. Girls have comparatively lower prevalence of anthropometric failure than boys in 2015 (APR $=0.87,95 \% \mathrm{CI}, 0.83-0.92$, $p<0.001)$. Birth weight was significantly associated with anthropometric failure in all surveys. In comparison with normal birth weight, the low birth weight children had higher prevalence of anthropometric failure in 2015 $(\mathrm{APR}=1.65,95 \% \mathrm{CI}, 1.48-1.82, p<0.001)$. In terms of diseases, both having diarrhea $(\mathrm{APR}=1.12,95 \% \mathrm{CI}$, $1.04-1.20, p=0.002)$ and fever (APR $=1.08,95 \% \mathrm{CI}$, $1.02-1.15, p=0.008)$ were associated with higher prevalence of anthropometric failure in 2005, and in 2015 $(\mathrm{APR}=1.07,1.0-1.14,95 \% \mathrm{CI}, p=0.044)$. Moreover, the prevalence of anthropometric failure were significantly higher for children who were born at home than those at health facilities in 2005 (APR $=1.16,95 \%$ CI, 1.061.27, $p=0.001$ ) (Table 4). Nevertheless, the sub-group analysis of children aged 6 to 23 months revealed that, 
Table 5 Crude and adjusted association between dietary diversity and anthropometric failure among children of 6-23 months of age in Tanzanian Demographic and Health Surveys (2005-2015)

\begin{tabular}{|c|c|c|c|c|c|c|c|c|c|}
\hline \multirow[t]{2}{*}{ Variables } & \multirow[b]{2}{*}{ N (\%) } & \multicolumn{2}{|c|}{ TDHS $2015(\boldsymbol{N}=3070)$} & \multirow[b]{2}{*}{ N (\%) } & \multicolumn{2}{|c|}{ TDHS $2010(\boldsymbol{N}=2207)$} & \multirow[b]{2}{*}{ N (\%) } & \multicolumn{2}{|c|}{ TDHS $2005(\boldsymbol{N}=2399)$} \\
\hline & & $\begin{array}{l}\text { Crude PR } \\
(95 \% \mathrm{Cl})\end{array}$ & $\begin{array}{l}\text { Adjusted PR } \\
(95 \% \mathrm{Cl})\end{array}$ & & $\begin{array}{l}\text { Crude PR } \\
(95 \% \mathrm{Cl})\end{array}$ & $\begin{array}{l}\text { Adjusted PR } \\
(95 \% \mathrm{Cl})\end{array}$ & & $\begin{array}{l}\text { Crude PR } \\
(95 \% \text { Cl) }\end{array}$ & $\begin{array}{l}\text { Adjusted } \mathrm{PR}^{\mathbf{a}} \\
(95 \% \mathrm{Cl})\end{array}$ \\
\hline \multicolumn{10}{|c|}{ Dietary Diversity } \\
\hline $\begin{array}{l}\geq 4 \text { food } \\
\text { groups }\end{array}$ & $788(25.6)$ & 1.0 & 1.0 & $220(10)$ & 1.0 & 1.0 & $349(14.5)$ & 1.0 & 1.0 \\
\hline $\begin{array}{l}<4 \text { food } \\
\text { groups }\end{array}$ & $2282(74.3)$ & $\begin{array}{l}1.11(0.99- \\
1.24)\end{array}$ & $\begin{array}{l}1.11(0.99- \\
1.24)\end{array}$ & $1987(90)$ & $\begin{array}{l}1.04(0.88- \\
1.21)\end{array}$ & $\begin{array}{l}1.05(0.89- \\
1.22)\end{array}$ & $2050(85.4)$ & $\begin{array}{l}1.05(0.92- \\
1.19)\end{array}$ & $\begin{array}{l}1.05(0.92- \\
1.19)\end{array}$ \\
\hline
\end{tabular}

a- Adjusted for gender, diarrhea, fever and place of residence; $1.0=$ Reference category, $\mathrm{Cl}=$ confidence interval; $\mathrm{PR}=\mathrm{Prevalence}$ ratio

the consumption of a diversified diet was not associated with anthropometric failure $(p>0.05)$ in any survey as shown in Table 5.

\section{Discussion}

This paper provides the new estimates for the prevalence of undernutrition by using an aggregate indicator of anthropometric failure and applying it to the large nationally representative datasets in Tanzania. It also describes the trends and examines the correlates associated with anthropometric failures. Our analysis shows how the conventional indices of stunting, wasting, underweight, when used on their own, miss significant numbers of children who experience multiple anthropometric deficits. We show that this can be avoided by using an aggregate measure known as the composite index of anthropometric failure (CIAF) [8]. The prevalence of CIAF stands at $38.2 \%$, which is significantly higher compared to the prevalence reported by conventional indices of stunting (34.4\%) wasting (4.5\%) and underweight (13.6\%) in 2015 [5]. In other countries the prevalence of CIAF was $47.8 \%$ in India [12]; 48.4\% in Ethiopia [17], 48.3\% in Bangladesh [15] and $21.7 \%$ in China [14]. Although the proportion of children with multiple anthropometric failure has declined from 2.2 to $1.5 \%$ in 2015 , it was reported in another study that these children have up to twelve times greater risk of early mortality [6]. Therefore, measurement of CIAF is very useful in the detection of children who are at higher risk of death associated with anthropometric failure.

This study further reports the existence of multiple factors influencing childhood undernutrition in Tanzania. Children, maternal, and household socioeconomic factors were found to be associated with anthropometric failure in various years. In comparison, a recent study conducted by Sunguya et al. [4], which aimed to examine the trends and factors associated with stunting in Tanzania revealed the risk factors that are similar to this study. Clearly, interventions targeting anthropometric failure would therefore be important for stunting reduction, especially given the close relationship between trends in prevalence of stunting and CIAF, as displayed in Fig. 1. Additionally, the datasets used and the number of children included by Sunguya et al. [4] are somewhat similar to this study. However, the study done by Sunguya et al. [4] may be suitable to inform interventions targeting at reduction of chronic undernutrition only, whereby, this study has the potential to ameliorate main drivers of all forms of undernutrition in the country.

In this study, anthropometric failure was strongly associated with characteristics of the household such as location, wealth status, and household head characteristics. This corresponds with findings from a systematic review, which reported that wealth and socio-economic factors were highly impacting the prevalence of anthropometric failure in many low- and middle-income countries including Tanzania [33]. Our study found that children living in rural areas have more prevalence of anthropometric failure compared to urban children. This is consistent with previous studies conducted in Bangladesh [15] and Myanmar [26], and is most likely linked to better living conditions and adequate all years-round food accessibility in urban areas. In addition, our findings show that children from poorer households are more likely to experience anthropometric failure compared with children from richer households. This corresponds to many other studies done previously in developing countries like Ethiopia [17], Bangladesh [15] and India [34]. Pomati et al. [35] analyzed the data of several West and Central African countries found that the risk of anthropometric failure among children in wealthier households is half than that of the poorest households. Similarly, highest wealth status was found to be associated with lower odds of undernutrition among children under-5 years old in Tanzania [4], and elsewhere [33]. This might be because poverty is closely associated with inadequate provision of nutritious food and poor sanitation. Both factors are likely to increase the risk for infections and ultimately lead to undernutrition among children [36, 37]. In addition, access to health care services may also be limited in poor households compared to the rich ones. 
We found that households headed by older parents are less likely to have children with anthropometric failure. Older parents most likely have more experience concerning childcare and thus make choices that are more informed on child health, and engage themselves in different knowledge activities than younger parents. In terms of marriage, we found that single mothers are more likely to have children with anthropometric failure than for married mothers. This is because, in many cases in the country, single mothers have low socioeconomic status due to divorce/separation, death of or sometimes abandonment by men. Therefore, they are sole providers and are responsible for childcare duties and income generation, leaving them more vulnerable to food insecurity than married mothers. Therefore, nutrition interventions of socioeconomically disadvantaged households may thus significantly reduce the burden of undernutrition in the country, as has been stated previously by Alderman et al. [38].

This study shows that both maternal and newborn health is an important factor to consider when addressing the nutrition status of children. In this study we see that, mother's nutritional status, birth weight of children, and place of delivery were associated with anthropometric failure in Tanzania. This calls for more efforts focusing on the nutrition of first 1000 days of life, from the conception up to 2 years. This study reveals that children who were born at home have a higher prevalence of anthropometric failure than those born at a health facility. This corresponds with a cross-sectional studies in Tanzania [4] and elsewhere [26]. Health facility delivery is very important because it help to receive appropriate and timely obstetric and medical care, as well as information about childcare to parents. Therefore, promoting health facility delivery can have beneficial effect not only on the mothers, but also on their children. On the other hand, good nutritional status of mothers can protect against anthropometric failure. Children of underweight mothers are more likely to get anthropometric failure than those of normal weight mothers. The plausible explanation for this may be poor nutritional status of mothers is a risk to infant deficiency and a risk factor for fetal growth restriction, resulting in low birth weight [39]. We also found that low birthweight have a strong positive relationship with anthropometric failure. This is comparable with findings from Sunguya et al. [4] who reported that children born with normal birth weight were $35 \%$ less likely to be stunted than low weight children.

Furthermore, biological factors of children like age and gender can highly influence undernutrition. Children in the youngest age group of 0-6 months had a significantly lower prevalence of anthropometric failure than in older age groups of above 6 months. These results are consistent with many other studies from other countries
$[15,24]$ as well as in Tanzania $[4,22,23]$. This may be due to breastfeeding practice for the younger children, as it is well established that adequate nutrition received from breast milk is enough even when a mother is undernourished. Available evidences are showing that in many countries, complementary feeding is inadequate and termination of breastfeeding starts before 6 months. Young children below the age of 2 years have to receive a diversified and adequate complementary feeding in order to be healthy and maintain good growth [30]. Surprisingly, in this study we did not find the association between consumption of a diversified diet and anthropometric failure of children between 6 to 23 months of age in any of the surveys. This study did not figure out the reasons for this observation, however; previous analysis have shown that dietary diversity was independent predictor of stunting and underweight only, but not wasting among children of 6 to 23 months [31]. Similar results have been reported among under-5 years children in Myanmar [26]. The WHO has recommended that an infant should receive a minimum diet diversity of at least four food groups out of seven in order to maintain proper growth and development [30]. We found that the majority $(\sim 70 \%)$ have not reached this recommendation, which implies low diet quality and finally may lead to undernutrition. Nevertheless, this study found that boys have higher prevalence of anthropometric failure compared to girls. This is not unexpected, a study by Wamani et al. [40] conducted among sub-Sahara African countries found that male children under-5 years of age are more likely to become undernourised than females. There is lack of scientific evidence to justify the presence of risk for boys toward undernutrition. Perhaps the morbidity pattern between male and female children could explain the phenomenon [40].

We also found that childhood anthropometric failure is significantly associated with mother's educational attainment. Children of mothers who are more educated tend to have a lower prevalence of anthropometric failure than those of uneducated mothers. Briefly, educational attainment of the mother may influence the nutritional status of a child in various ways. For example, well-educated women tend to have better work opportunities and obtain higher incomes that may results to higher socioeconomic status. Another reason could be that more educated mothers could understand maternal and childcare education and information provided through different media compared to mothers with low education. Endris et al. [17] evaluated the risk factors of undernutrition among children aged 0-59 months in rural Ethiopia and reported that, the odds of being undernourished was 1.32 times higher for children whose mothers did not have any basic education compared to children whose mothers attended primary 
education. This observation is comparable to our results. The relationship between mother's education and child nutritional status have been well documented in several other studies [25, 41-43]. This study together with the above literature highlight the importance of women education in improving child nutrition status.

Although this study provides a clear picture on the burden and correlates of CIAF from the national representative data in Tanzania, some general limitations should be considered. Analysis on the prevalence and trends included six surveys while factors associated with CIAF were only identified from three recent surveys. It is possible that older surveys could show different associated factors compared to most recent studies. However, the three surveys included that were the most recent ones provide information on the possible areas of intervention. In addition, data on other factors that may contribute to CIAF were not included in this study, for example, data on water hygiene and sanitation and other childcare practices that may contribute to CIAF. It is therefore important to consider these factors in future studies. Despite the above limitations, we hope this study will shed light on key areas for interventions in Tanzania. In addition, this study used large population based data with a representative sample size at national, regional, rural and urban areas, which provides most robust estimates of the whole country, so it can be easily generalized.

\section{Conclusion}

One in every three under-five children are suffering from various forms of anthropometric failure in Tanzania. There is a decline in the overall burden of undernutrition in Tanzania as measured by CIAF. Multiple factors including those related to mothers, children and household socioeconomic characteristics have the potential to influence childhood undernutrition. Therefore, efforts to reduce the burden of undernutrition should focus on reducing poverty and raising people's living standards and women's education. This will include improving the quality of their homes, providing education, and provide equal access to maternal and child health care services for both rural and urban areas.

\section{Abbreviations \\ APR: Adjusted prevalence ratio; BMI: Body mass index; Cl: Confidence intervals; CIAF: Composite index of anthropometric failure; HAZ: Height-for- age Z-scores; ICF: Inner city funds; IYCF: Infant and young child feeding; MDD: Minimum dietary diversity; SD: Standard deviation; TDHS: Tanzania demographic and health survey; UNICEF: United Nations international children's fund; WAZ: Weight-for-age Z-scores; WHO: World health organization; WHZ: Weight-for-height Z-scores}

\section{Acknowledgements}

We thank the support in terms of training and capacity building received from the consortium Afrique One African Science Partnership for Intervention Research Excellence [Afrique One-ASPIRE /DEL-15-008].
Authors' contributions

AGK and AWM conceived the study and wrote the manuscript. AGK analyzed and interpreted the data. KK and GK critically revised and edited the manuscript. All authors have reviewed and approved last version of the manuscript.

\section{Funding}

No funding was required.

\section{Availability of data and materials}

Data for this study are available upon request from the DHS portal (www. dhsprogram.com).

\section{Ethics approval and consent to participate}

Relevant authorities in Tanzania mainland and Zanzibar approved the TDHS protocols and data collection procedures. These include the National Institute of Medical Research (NIMR), Zanzibar Medical Research Ethical Committee (ZAMREC), the Institutional Review Board of ICF International, and the Centers for Disease Control and Prevention in Atlanta [2]. Since we only used secondary data, personal consents was not required, as well as no any personal identity being identified from the data files. The data were completely anonymous. We would like to acknowledge the ICF International (www.dhsprogram.com) to give us access to the dataset.

\section{Consent for publication}

Not applicable for this study.

\section{Competing interests}

The authors declare that there is no any conflict of interest.

\section{Author details}

'Department of Epidemiology and Biostatistics, Muhimbili University of Health and Allied Sciences, Dar-es-Salaam, Tanzania. ${ }^{2}$ Department of Food Technology, Nutrition and Consumer Sciences, Sokoine University of Agriculture, Chuo Kikuu, Morogoro, Tanzania. ${ }^{3}$ School of Life Sciences and Bio-Engineering, Nelson Mandela African Institution of Science and Technology, Arusha, Tanzania. ${ }^{4}$ Department of Environmental Health and Ecological Sciences, Ifakara Health Institute, Dar-es-Salaam, Tanzania.

Received: 22 May 2020 Accepted: 30 July 2020

Published online: 04 September 2020

References

1. Bryce J, Boschi-Pinto C, Shibuya K, Black RE. WHO estimates of the causes of death in children. Lancet. 2005;365.

2. Ministry of Health, Community Development, Gender, Elderly and Children (MoHCDGEC) [Tanzania Mainland], Ministry of Health (MoH) [Zanzibar], Tanzania Food and Nutrition Centre (TFNC), National Bureau of Statistics (NBS), Office of the Chief Government Statistician (OCGS) [Zanzibar] and UNICEF. Tanzania National Nutrition Survey using SMART Methodology (TNNS) 2018. Dar es Salaam, Tanzania: MoHCDGEC, MoH, TFNC, NBS, OCGS, and UNICEF; 2018

3. WHO: Physical status and the use and interpretation of anthropometry. Reports of WHO expert committee. Technical Report Series: No. 854, Geneva, Switzerland, p 13-125. In.; 2006.

4. Sunguya BF, Zhu S, Mpembeni R, Huang J. Trends in prevalence and determinants of stunting in Tanzania: an analysis of Tanzania demographic health surveys (1991-2016). Nutr J. 2019:18(1):85.

5. Ministry of Health, Community Development, Gender, Elderly and Children (MoHCDGEC) [Tanzania Mainland] ,Ministry of Health (MoH) [Zanzibar], National Bureau of Statistics (NBS), Office of the Chief Government Statistician (OCGS), and ICF, 2016. Tanzania Demographic and Health Survey and Malaria Indicator Survey (TDHS-MIS) 2015-16. Dar-es-Salaam, Tanzania, and Rockville, Maryland, USA: MoHCDGEC, MoH, NBS, OCGS, and ICF; 2016.

6. McDonald CM, Olofin I, Flaxman S, Fawzi WW, Spiegelman D, Caulfield LE, Black RE, Ezzati M, Danaei G. The effect of multiple anthropometric deficits on child mortality: meta-analysis of individual data in 10 prospective studies from developing countries. Am J Clin Nutr. 2013;97(4):896-901.

7. Svedberg P. Poverty and undernutrition: theory, measurement, and policy: Clarendon press; 2000. https://doi.org/10.1093/0198292686.001.0001. 
8. Nandy S, Irving M, Gordon D, Subramanian SV, Smith GD. Poverty, child undernutrition and morbidity: new evidence from India. Bull World Health Organ. 2005;83(3):210-6.

9. Nandy S, Miranda JJ: Overlooking undernutrition? Using a composite index of anthropometric failure to assess how underweight misses and misleads the assessment of undernutrition in young children. Soc Sci Med 2008, 66(9):1963-11966.

10. Samuel F. Assessing the prevalence of Undernutrition using the composite index of anthropometric failure (CIAF) among young children in a rural community in Oyo state, Nigeria. Niger J Nutr Sci. 2014;35(2).

11. Mukhopadhyay DK, Biswas R, Chakraborty M, Sadhukhan SK, Banik KK. Anthropometric failure, a new approach to measure undernutrition: an experience from a rural community of West Bengal, India. J Indian Med Assoc. 2009;107(4):211-4 236

12. Savanur MS, Ghugre PS. Magnitude of undernutrition in children aged 2 to 4 years using CIAF and conventional indices in the slums of Mumbai city. J Health Popul Nutr. 2015;33(1):3.

13. Seetharaman $N$, Chacko T, Shankar S, Mathew A. Measuring malnutrition -the role of Z scores and the composite index of anthropometric failure (CIAF). Indian J Community Med. 2007;32(1):35-9.

14. Pei $L$, Ren $L$, Yan $H$. A survey of undernutrition in children under three years of age in rural Western China. BMC Public Health. 2014;14(1):121.

15. Islam, MS, Biswas, T. Prevalence and correlates of the composite index of anthropometric failure among children under 5 years old in Bangladesh. Matern Child Nutr. 2020;16:e12930. https://doi.org/10.1111/mcn.12930

16. Bejarano IF, Oyhenart E, Torres MF, Cesani MF, Mariela G, Navazo B, Zonta M, Luis M, Quintero F, Dipierri J, et al. Extended composite index of anthropometric failure in Argentinean preschool and school children. Public Health Nutr. 2019;22:1-9.

17. Endris $\mathrm{N}$, Asefa $\mathrm{H}$, Dube L. Prevalence of malnutrition and associated factors among children in rural Ethiopia. Biomed Res Int. 2017;2017.

18. Ziba M, Kalimbira AA, Kalumikiza Z. Estimated burden of aggregate anthropometric failure among Malawian children. S Afr J Clin Nutr. 2018; 31(2):43-6.

19. Black RE, Allen LH, Bhutta ZA, et al. Maternal and child undernutrition: global and regional exposures and health consequences. Lancet. 2008; 371(9608):243-60. https://doi.org/10.1016/50140-6736(07)61690-0.

20. Caulfield LE, de Onis M. Blossner M, Black RE. Undernutrition as an underlying cause of child deaths associated with diarrhea, pneumonia, malaria, and measles. Am J Clin Nutr. 2004;80(1):193-8.

21. UNICEF; $W H O$; Bank W. Joint child malnutrition estimates. Levels and trends in child malnutrition: Key findings of the 2015 edition. In: Global Database on Child Growth and Malnutrition. New York, NY: UNICEF, WHO, \& World Bank Group; 2015.

22. Ahmed MM, Hokororo A, Kidenya BR, Kabyemera R, Kamugisha E. Prevalence of undernutrition and risk factors of severe undernutrition among children admitted to Bugando medical Centre in Mwanza, Tanzania. BMC Nutr. 2016;2(1):49

23. Chirande L, Charwe D, Mbwana $H$, et al. Determinants of stunting and severe stunting among under-fives in Tanzania: evidence from the 2010 cross-sectional household survey. BMC Pediatr. 2015;15:165. https://doi.org/ 10.1186/s12887-015-0482-9.

24. Kejo D, Mosha TCE, Petrucka P, Martin H, Kimanya ME. Prevalence and predictors of undernutrition among underfive children in Arusha District, Tanzania. Food Sci Nutr. 2018;6(8):2264-72.

25. Poda GG, Hsu CY, Chao JC. Factors associated with malnutrition among children $<5$ years old in Burkina Faso: evidence from the demographic and health surveys IV 2010. Int J Qual Health Care. 2017;29(7):901-8.

26. Kang $Y$, Kim J. Risk factors for undernutrition among children 0-59 months of age in Myanmar: Evidence from the Demographic and Health Survey 2015-16. Matern Child Nutr. 2019:e12821. https://doi.org/10.1111/mcn. 12821.

27. Haidar J, Abate G, Kogi-Makau W, Sorensen P. Risk factors for child undernutrition with a human rights edge in rural villages of north Wollo, Ethiopia. East Afr Med J. 2005;82(12):625-30.

28. WHO. Global nutrition targets 2025: Policy brief series: World Health Organization; 2014. Available at https:/www.who.int/nutrition/publications/ globaltargets2025_policybrief_overview/en/. Accessed 20 May 2020.

29. UN: Transforming our world : the 2030 Agenda for Sustainable Development, 21 October 2015, A/RES/70/1 available at: https://www. refworld.org/docid/57b6e3e44.html [accessed 10 April 2019]. 2015.
30. WHO. Indicators for assessing infant and young child feeding practices: Part 1 Definitions. Conclusions of a consensus meeting held 6-8 November 2007 in Washington D.C., USA. Geneva: World Health Organization; 2008.

31. Khamis AG, Mwanri AW, Ntwenya JE, Kreppel K. The influence of dietary diversity on the nutritional status of children between 6 and 23 months of age in Tanzania. BMC Pediatr. 2019;19(1):518.

32. Pearce N. Effect measures in prevalence studies. Environ Health Perspect. 2004;112(10):1047-50.

33. Vollmer S, Harttgen K, Kupka R, Subramanian S. Levels and trends of childhood undernutrition by wealth and education according to a composite index of anthropometric failure: evidence from 146 demographic and health surveys from 39 countries. BMJ Glob Health. 2017;2(2):e000206.

34. Dasgupta PA, Parthasarathi R, Prabhakar V, Biswas R, Geethanjali A. Assessment of under nutrition with composite index of anthropometric failure (CIAF) among under-five children in a rural area of West Bengal. Indian J Community Health. 2014;26:132-8.

35. Pomati M, Nandy S. Assessing Progress towards SDG2: trends and patterns of multiple malnutrition in young children under 5 in west and Central Africa. Child Indic Res. 2019. https://doi.org/10.1007/s12187-019-09671-1.

36. Mshida HA, Kassim N, Mpolya E, Kimanya M. Water, sanitation, and hygiene practices associated with nutritional status of under-five children in semipastoral communities Tanzania. Am J Trop Med Hyg. 2018;98(5):1242-9.

37. Raihan MJ, Farzana FD, Sultana S, Haque MA, Rahman AS, Waid JL, McCormick B, Choudhury N, Ahmed T. Examining the relationship between socio-economic status, WASH practices and wasting. PLoS One. 2017;12(3): e0172134.

38. Alderman $\mathrm{H}$, Hoogeveen $\mathrm{H}$, Rossi M. Reducing child malnutrition in Tanzania: combined effects of income growth and program interventions. Econ Hum Biol. 2006;4.

39. WHO. Infant and young child feeding available at [ https://www.who.int/ news-room/fact-sheets/detail/infant-and-young-child-feeding]. Accessed 20 May 2020.

40. Wamani H, Astrom AN, Peterson S, Tumwine JK, Tylleskar T. Boys are more stunted than girls in sub-Saharan Africa: a meta-analysis of 16 demographic and health surveys. BMC Pediatr. 2007;7:17.

41. Talukder A. Factors associated with malnutrition among under-five children: Illustration using Bangladesh demographic and health survey, 2014 data. Children. 2017:4(10):88

42. Abuya BA, Ciera J, Kimani-Murage E. Effect of mother's education on child's nutritional status in the slums of Nairobi. BMC Pediatr. 2012;12:80.

43. Nankinga O, Kwagala B, Walakira EJ. Maternal employment and child nutritional status in Uganda. PLoS One. 2019;14(12):e0226720.

\section{Publisher's Note}

Springer Nature remains neutral with regard to jurisdictional claims in published maps and institutional affiliations.

\section{Ready to submit your research? Choose BMC and benefit from:}

- fast, convenient online submission

- thorough peer review by experienced researchers in your field

- rapid publication on acceptance

- support for research data, including large and complex data types

- gold Open Access which fosters wider collaboration and increased citations

- maximum visibility for your research: over $100 \mathrm{M}$ website views per year

At $\mathrm{BMC}$, research is always in progress.

Learn more biomedcentral.com/submission 